\title{
Psychometric evaluation of fear of COVID-19 Scale (FCV-19S) among Chinese primary and middle schoolteachers, and their students
}

\author{
I-Hua Chen ${ }^{1} \cdot$ Chao-Ying Chen ${ }^{2} \cdot$ Ke-Yun Zhao ${ }^{3}$ Jeffrey H. Gamble ${ }^{4} \cdot$ Chung-Ying Lin $^{5,6,7}$ (D) Mark D. Griffiths ${ }^{8}$. \\ Amir H. Pakpour ${ }^{9}$
}

Accepted: 1 November 2021

(c) The Author(s), under exclusive licence to Springer Science+Business Media, LLC, part of Springer Nature 2021

\begin{abstract}
Utilizing a large-scale cross-sectional survey, the present study tested the advanced psychometric properties of Fear of COVID-19 Scale (FCV-19S) in specific populations (i.e., primary and middle schoolteachers, and their students). The present study also examined the association between perceived fear of COVID-19 and psychological distress among home-room teachers (i.e., teachers who teach all their students in one classroom all day) and their students. The results among participants $(11,134$ teachers and 4,335 students) indicated good internal reliability of FCV-19S and excellent factorial validity with a two-factor structure utilizing these specific populations. Furthermore, the multilevel analysis showed that home-room teachers' psychological distress, but not fear of COVID-19, was positively associated with their students. In sum, the FCV-19S is a useful tool to assess the fear of COVID-19 on potentially vulnerable populations (i.e., primary/middle schoolteachers and their students). Future studies are encouraged to use the present study's findings to investigate possible underlying mechanisms for developing effective coping strategies and interventions.
\end{abstract}

Keywords COVID-19 $\cdot$ fear of COVID-19 $\cdot$ Fear of COVID-19 Scale $\cdot$ psychometrics $\cdot$ students $\cdot$ teachers

\section{Introduction}

It has been over 18 months since the World Health Organization (WHO) declared the novel coronavirus disease 2019 (COVID-19) as a global pandemic (WHO, 2021a). Despite the worldwide spread of COVID-19, it has been under control in some countries (WHO, 2021b). However, many

Chao-Ying Chen

chao-ying.chen@gap.cgu.edu.tw

$\triangle$ Chung-Ying Lin cylin36933@gmail.com

1 Chinese Academy of Education Big Data, Qufu Normal University, Qufu City, Shandong, China

2 School of Physical Therapy and Graduate Institute of Rehabilitation Science, College of Medicine, Chang Gung University, No. 259, Wenhua 1st Road, Guishan District, Taoyuan City 333, Taiwan

3 School of Communication, Qufu Normal University, Rizhao City, Shandong, China

4 Department of Foreign Languages, National Chiayi University, Chiayi, Taiwan scholars believe the virus will not disappear in the near future (Nkwayep et al., 2020; Pak et al., 2020). The impact of COVID-19 on human society have been huge at both the macro level (e.g., the economy of the whole country) (Ashraf, 2020) and the micro level (e.g., individuals' daily life) (Lin, 2020; Tull et al., 2020). Because of the concerning figures related to COVID-19 (e.g., in Piroth et al., 2021's

5 Institute of Allied Health Sciences, College of Medicine, National Cheng Kung University, 1 University Rd, Tainan 701, Taiwan

6 Department of Occupational Therapy, College of Medicine, National Cheng Kung University, 1 University Rd, Tainan 701, Taiwan

7 Biostatistics Consulting Center, National Cheng Kung University Hospital, College of Medicine, National Cheng Kung University, 1 University Rd, 701 Tainan, Taiwan

8 International Gaming Research Unit, Psychology Department, Nottingham Trent University, Nottingham, UK

9 Department of Nursing, School of Health and Welfare, Jönköping University, Jönköping, Sweden 
study, the in-hospital mortality rate among adolescents was ten times higher for COVID-19 than for influenza), there is a natural fear of the pandemic worldwide (Asmundson $\&$ Taylor, 2020; Lin et al., 2020; Schimmenti et al., 2020). Although fear is a normal emotion that is activated to respond to threatening situations (Schimmenti et al., 2020), which is helpful in facilitating protective behaviors (e.g., washing hands more, keeping physically distanced, etc.), excessive fear of COVID-19 may cause severe psychological distress (e.g., posttraumatic stress symptoms and anxiety) (Asmundson \& Taylor, 2020; Caycho-Rodríguez et al., 2021a; Chi et al., 2021; Ho et al., 2005; Lin et al., 2020; Masuyama et al., 2020; Soraci et al., 2020; Wheaton et al., 2012). Therefore, monitoring fear of COVID-19 among different populations and cohorts is crucial.

In order to assess the fear of COVID-19, Ahorsu et al. (2020) developed a brief and valid instrument, the sevenitem Fear of COVID-19 Scale (FCV-19S). Compared to other instruments which have been developed to evaluate the fear of COVID-19, such as the Fear of the Coronavirus Questionnaire (FCQ) (Mertens et al., 2020), COVID Stress Scales (CSS) (Taylor et al., 2020), and single-item instruments (i.e., 'How would you currently rate your fear of COVID-19?') (Fitzpatrick et al., 2020), the FCV-19S has a number of key advantages. First, the FCV-19S has very good psychometric properties (Ahorsu et al., 2020) and has fewer items compared to other scales. More specifically, the FCQ has eight items, the CSS has 36 items, and the singleitem instrument may be questioned due to its reliability and validity (e.g., internal consistency cannot be calculated for a single-item instrument) (Fisher et al., 2016). Second, the FCV-19S has been translated into more than 20 languages. Therefore, engaging in this instrument is of great utility when making the international comparisons to address this global pandemic. For example, the FCV-19S has been translated and tested upon: general adult population in Portugal (Soares et al., 2021), New Zealand (Winter et al., 2020), Norway (Iversen et al., 2021), Iran (Ahorsu et al., 2020) and Italy (Soraci et al., 2020); Bangladeshis general population (aged 10 years and older) (Sakib et al., 2020), Peruvian older adults (aged over 60 years) (Caycho-Rodríguez et al., 2021b), Chinese primary school students, middle school students, and general adult population (Chi et al., 2021), and Japanese adolescents (Masuyama et al., 2020). Moreover, some scholars have reported that the FCV-19S is measurement invariant across countries (Caycho-Rodríguez et al., 2021; Lin et al., 2021).

Although the FCV-19S has shown very good psychometric properties in different ethnic populations (Ahorsu et al., 2020; Caycho-Rodríguez et al., 2021a; Chi et al., 2021; Iversen et al., 2021; Masuyama et al., 2020; Sakib et al., 2020; Soares et al., 2021; Soraci et al., 2020; Winter et al., 2020) and patients with chronic diseases (Chang et al.,
2020), the instrument has rarely been tested on specific occupations that have had to change the way they work due to COVID-19. Therefore, there is a knowledge gap regarding the fear of COVID-19 because if there is no psychometric evidence concerning the use of this instrument on these kinds of sub-groups, it will limit the use of this tool in clinical interventions for these populations in the future. In fact, fear of COVID-19 is not uniformly distributed (Fitzpatrick et al., 2020) and geographical location has influenced people's perception of fear of the pandemic intensively (Dillard et al., 2020; Li, 2021). In Fitzpatrick et al.'s (2020) study, there was higher perceived fear in the places where there were the highest number of reported COVID-19 cases. Generally speaking, fear is an emotion occurring when individual perceives the environment as containing a risk against the goal of maintaining well-being (Lazarus, 1991). According to the social amplification of risk model, the perceptions of the risks are more strongly related to their exposure to the risk rather than the magnitude of the risk itself (Renn et al., 1992). As such, those who have to be exposed to an environment full of COVID-19 information (representing a risk) for a long time because of their work, the degree of their pandemicrelated fear is worthy of attention.

The present study focused on a specific occupation, namely, primary and middle schoolteachers, who have had to change their accustomed teaching way to an unfamiliar environment (i.e., online teaching), responding to a compulsory restriction measure imposed by the government (Aliyyah et al., 2020; Aperribai et al., 2020; Fauzi \& Khusuma, 2020; Shen et al., 2020; Zheng \& Song, 2020). While the internet offers an alternative to uninterrupted schooling for teachers and students, it can also be a place that feeds the fears of internet users because of the high daily rates of new cases and deaths together with the bombardment of pandemic information via the media and social media (Gao et al., 2020; Rodríguez-Hidalgo et al., 2020). Furthermore, the repeated COVID-19 coverage may also instill fear among the general public. A content analysis of COVID-19 coverage on global media demonstrated that fear was the second largest dominant theme and that the media generally sensationalized the stories potentially heightening the fear of COVID-19 among the public (Ogbodo et al., 2020). In Li's (2021) longitudinal study, the frequency exposure to COVID-19 news from the media (including internet, television and radio) significantly predicted people's later fear regardless of their perceptions of such media coverage. Joining these strands together, there is reason to believe that since primary and middle schoolteachers have been spending more time on the internet than they usually do to prepare and implement online teaching (Aperribai et al., 2020; Shen et al., 2020), this long exposure time on internet increases the likelihood of receiving more information concerning COVID-19 from 
social media applications reporting coverage or breaking news (e.g., announcements related to deaths and infections locally, nationally and/or internationally). In these cases, primary and middle schoolteachers may become a highrisk sub-group of experiencing the fear of COVID-19.

In addition, teachers may also actively search the information about COVID-19 to keep updated concerning the pandemic (including the recent news of the pandemic), to monitor the associated regulation changes to better communicate with their stakeholders (i.e., students and parents), and to subsequently adjust their teaching (including methods and content). Although there is no direct evidence showing that teachers would seek out more information concerning COVID-19, several studies have noted that teachers feel a highly degree of uncertainty regarding the pandemic, because they are very eager to know how long their online teaching will last and whether courses will end in online or offline environments (Eşici et al., 2021; Khanal et al., 2021; Kim \& Asbury, 2020; Kulikowski et al., 2021; Lepp et al., 2021; MacIntyre et al., 2020). Given that uncertainty is the antecedent variable of information-seeking (Wilson et al., 2002), it is reasonable to presume teachers would exhibit more informationseeking behavior regarding COVID-19. Unfortunately, evidence has already shown a close relationship between information-seeking behaviors via the internet (or other kinds of media) and people's fear levels (Huang et al., 2020; Superio et al., 2021). It is likely that as people are exposed to risk-based information, the perception of uncertainty (as a metacognition) is elicited and this contributes to information-seeking behavior mediated by danger emotion appraisal (e.g., fear, anxiety, and worry) (Huang et al., 2020). Furthermore, the relationship between perceived fear of the pandemic and information-seeking may be reciprocal. In a longitudinal study, fear of Zika amplified informationseeking from Time 1 to Time 2, then information-seeking amplified fear from Time 2 to Time 3, over a two-month period (Dillard et al., 2020).

Based on the aforementioned literature, it is highly possible that teachers may have an easily-induced fear emotion related to COVID-19 through both passive routes (e.g., automatic updates of online COVID-19 breaking news) and active routes (e.g., through intentional searching for COVID-19 information). Due to the global outbreak of the pandemic and its serious impact on people's wellbeing, many studies have highlighted that teachers have the important task of not only online subject teaching, but also monitoring their students' mental health through pastoral care (Eşici et al., 2021; Kaden, 2020; Kim et al., 2020). For teachers with such important responsibilities, it is very important to understand their level of fear of COVID-19 and associated mental health illnesses. Such information will provide valuable insights for future response strategies when schools are closed due to the pandemic.

\section{The aims of the present study}

Although being restricted to work from home might reduce the fear of bodily contact, the domains involved in COVID-19 fear is not limited to the body, but also includes interpersonal relationships (e.g., fear for significant others' safety) and cognitive domains (e.g., fear of knowing and fear of not knowing pandemic-related information) (Schimmenti et al., 2020). The fear from these domains cannot be blocked by the restriction measures but can grow via internet use. Therefore, a population of primary and middle schoolteachers who are required to use the internet more often is worthy of further invesigation. To the best of the present authors' knowledge, there is no psychometric evidence for the FCV-19S on this sub-group. To bridge the knowledge gap, the present study evaluated the psychometric properties of the FCV-19S among primary and middle schoolteachers. Moreover, because engaging in online teaching during the outbreak of COVID-19 might be a critical factor affecting the level of fear of COVID-19, the present study divided primary and middle schoolteachers into two categories: those who engaged in online teaching during the pandemic period and those who did not.

Apart from the teachers, children and adolescents were also included in the present study to further evaluate the psychometric properties of the FCV-19S with a much larger sample size because very few psychometric FCV19S studies have been implemented utilizing these groups. Scholars have noted that the FCV-19S has mostly been validated among middle-aged adults, a relatively less vulnerable group of people, and therefore recommended the instrument needed to be examined among vulnerable populations, including the elderly, children, adolescents, and young adults in the future (Pakpour et al., 2020; Ransing et al., 2020). In fact, the severity of fear of COVID-19 among pre-university students is unclear and the findings have been mixed.

Lin et al. (2021) used data from 11 different countries to test the psychometric properties of FCV-19S. They found individuals aged below 18 years had significantly lower latent scores than middle-aged adults. However, evidence demonstrated that children and adolescents had higher fear of COVID-19 than adults. Chi et al. (2021) reported that the FCV-19S scores of students below the age of 18 years with similar findings reported in Turkey (Gozpinar et al., 2021) and Japan (Masuyama et al., 2020) (see the Table S1 in appendix). It should be noted that the aforementioned studies (i.e., Chi et al., 2021; Gozpinar et al., 2021; Lin et al., 2021; Masuyama et al., 2020) 
all recruited relatively small numbers of children and adolescents (all under 1000 participants). This suggests a large-scale survey is needed to provide answers concerning two perspectives: (i) primary and middle school students have lower levels of COVID-19 fear because they may not consider COVID-19 a serious problem and/or do not fully understand the threat of the virus because they do not need to face the difficult challenges resulting from COVID-19 (e.g., financial burden) (Lin et al., 2021); or (ii) primary and middle school students have higher levels of COVID-19 fear due to a more irrational perception because their cognitions are developmentally immature (Chi et al., 2021).

Based on the above, the first objective in the present study was to assess the psychometric properties of FCV$19 \mathrm{~S}$ among three groups (i.e., teachers engaged in online teaching, teachers not engaged in online teaching, and their students). A multiple-group analysis was used to test whether the measurement invariance of FCV-19S existed across the three groups. More specifically, based on the results of the model fit tests, the specific factor structures were tested by conducting the further tests of measurement invariance.

The second objective was to examine the association between perceived fear of COVID-19 and general psychological distress among teachers and their students. Given that emotion is contagious (Wild et al., 2001), the present study hypothesized there would be an association between fear of COVID-19 and general psychological distress among students and their respective teachers. More specifically, according to ecological systems theory, students' development is cultivated through the interactions with teachers within the school microsystem (Bronfenbrenner, 1992; Neal \& Neal, 2013). Although the school campuses were closed during the outbreak of COVID-19 pandemic, teachers still used the internet or smartphone applications to facilitate learning, homework, and daily living in some countries ( $\mathrm{He} \& \mathrm{Li}, 2020$; Yao, 2021). Consequently, the fear of COVID-19 and/or psychological distress may have developed between students and teachers through the interactive online community. To the best of the present authors' knowledge, this association from two hierarchical levels (i.e., the nested data: classroom students were nested in their teacher's class) has not been tested in the mental health studies engaging in on the impact from COVID-19.

Following the aforementioned objectives, the present study attempted to answer two specific research questions (RQs): RQ1: What are the psychometric properties (i.e., internal reliability, construct and concurrent validity, measurement invariance) of FCV-19S across the three populations (i.e., teachers engaged in/not engaged in online teaching and their respective students); RQ2: Does the students' perceived fear of COVID-19 and their psychological distress correlate with their respective teachers on these same constructs?

\section{Methods}

In this section, all data exclusions, all manipulations, and all measures in the study are reported.

\section{Participants}

A cross-sectional online survey was administered to schoolteachers (primary and middle school) and their respective students between May 25 and June 30, 2020. Ethics approval for the study was provided by the Institutional Review Board (IRB) of the Jianxi Psychological Consultant Association (IRB ref of teachers: JXSXL2020-J013; IRB ref of students: JXSXL-2020-MY14).

In order to collect data reflecting the initial launch of online teaching by schoolteachers, a timely survey was deemed necessary (i.e., before the end of the semester) and this made it difficult to comprehensively sample from all provinces in mainland China. Consequently, a non-probability sampling strategy was adopted. More specifically, the research team selected a province from the western (Sichuan), central (Jiangxi), and eastern (Shandong) region of mainland China which covered half of the population distribution area in the country. The team sought help from principals of primary and middle schools in these three provinces. Subsequently, the online survey's hyperlink was sent to the principals who accepted the research team's invitation and these principals forwarded the hyperlink to their respective school's teachers. The online survey was voluntary and anonymous. Informed consent was obtained at the beginning of the survey. In total, 11,134 schoolteachers (mean age $=34.87$ years, $\mathrm{SD}=4.85$ ) completed the online survey. Among them, 9150 teachers used online teaching during school closure, while 1984 teachers did not engage in online courses due to the subject not being able to easily implement online (e.g., gym class, music class, art class). Moreover, among the teachers using online teaching, 120 were home-room teachers (also called tutors in some countries) (mean age $=35.20$ years, $\mathrm{SD}=3.89$ ). Home-room teachers are those who not only teach a subject but also need to take responsibility for an exclusive class, including the keeping of a class register, dealing with discipline problems, and organizing extracurricular activities (Michalova et al., 2002). For these 120 home-room teachers, due to the long period of time in getting along with their responding class (even during the period of school campus closure, home-room teachers 
were required to keep contact with the responding students every day via the internet in mainland China $[(\mathrm{He} \& \mathrm{Li}$, 2020; Yao, 2021; Zhou \& Li, 2020]), the sample was suitable to test RQ2 concerning the relationship between students and teachers in terms of perceived fear of COVID-19 and their psychological distress. Therefore, the research team administered the online surveys to all the students in the 120 home-room teachers' classes and 4,335 respective students (mean age $=13.32$ years, $\mathrm{SD}=3.45$ ) completed the online survey. The number of students in a class for which a home-room teacher is responsible was approximately 35-40. All the online surveys were implemented utilizing Sojump (a platform for online questionnaire collection).

In order to analyze the representativeness of the participating schoolteachers, the key demographic variables were compared to the overall population statistics (i.e., the whole primary and middle schoolteachers in mainland China). The results demonstrated that only small effect sizes were found in terms of age, school type, sex, years of work experience, and school ownership (see the Table S2 in the appendix). These differences were statistically significant most likely due to large sample size $(11,134$ participants) but were not of practical significance.

\section{Measures}

In addition to instruments assessing fear of COVID-19 and psychological distress, key information concerning teachers' demographic variables was also collected: (i) whether they engaged in online teaching during the school closure. This was assessed to differentiate two types of teachers and the item was "During the pandemic, did you conduct online teaching (including online teaching, assigning and grading homework in the internet environment)?; and (ii) information concerning class identity which was used to establish any associations between home-room teachers and their respective students. Regarding the test of the concurrent validity, psychological distress was selected for two reasons. The first is that in an environment that provides a constant threat to personal safety, fear as a fundamental survival mechanism, and can easily become excessive (in the form of an anxiety disorder) and if the emotional responses fail to extinguish (e.g., due to the continued reporting of COVID-19 deaths), it can lead to various psychological and mental disorders (Shin \& Liberzon, 2010). Furthermore, evidence has shown there is a close relationship between COVID-19 fear level and the anxiety among teachers during the pandemic (Li et al., 2020) and that most of the psychometric studies examining the FCV-19S have included psychological distress as the criterion variable in these studies (e.g., Ahorsu et al., 2020; Alyami et al., 2020; Bitan et al., 2020; Chi et al., 2021;
Caycho-Rodríguez et al., 2021a; Chang et al., 2020; Sakib et al., 2020; Soraci et al., 2020).

\section{Fear of COVID-19 Scale}

The FCV-19S was originally developed by Ahorsu et al. (2020) and the Chinese version of FCV-19S was translated by Chi et al. (2021). The FCV-19S contains seven items assessing individuals' fear of COVID-19 (sample items: "It makes me uncomfortable to think about COVID-19"; "I cannot sleep because I' $m$ worrying about getting COVID19 "). Items are scored on a five-point scale from 1 ("totally disagree") to 5 is ("completely agree"). Higher scores on the FCV-19S indicate higher degrees of COVID-19 fear. The results of the psychometric properties are provided in the 'Results' section.

\section{Psychological distress}

The 21-item Depression, Anxiety and Stress Scale (DASS21; Lovibond \& Lovibond, 1996) was used as the indicators for psychological distress and which was served as the criterion variable. The DASS- 21 comprises three subscales: depression, anxiety, and stress (i.e., each subscale consisting of seven items). Sample items for each subscale include: "Felt that I had nothing to look forward to" (depression); "I was worried about situations in which I might panic and make a fool of myself" (anxiety); and "Found it difficult to relax" (stress). All items are rated engaging on a four-point scale (from 0 to 3), with higher scores indicating higher levels of depression, anxiety, or stress. The Chinese version of DASS-21 has robust psychometric properties (C. Wang et al., 2020; K. Wang et al., 2016) among Mainland Chinese respondents. The internal consistency of the Chinese DASS21 utilized in the present study was high for all the participants, including teachers (McDonald's $\omega=0.92,0.91$, and 0.91 for depression, anxiety, and stress, respectively) and students (McDonald's $\omega=0.89,0.88$, and 0.86 for depression, anxiety, and stress, respectively).

\section{Statistical analysis}

Because the participants included primary and middle schoolteachers, the present study firstly clarified if it was appropriate to pool all teachers into the same dataset. Independent $t$-tests were used to examine the differences in observed scores on FCV-19S (including each item and the overall scale) and DASS-21 (including the average score of the three subscales and the overall scale). The results demonstrated that significant differences were only found on three items in FCV-19S (see the Table S3 in the Appendix) while no significant differences were found on the other four items. Most importantly, even for those items with a significant 
difference, the corresponding effect sizes were low (Cohen's $d$ was between 0.01 to 0.09 ). According to Cohen (1988), as the value of $d$ was less than 0.20 , the difference was negligible. This indicated no substantial differences between primary and middle schoolteachers. Moreover, primary and middle schoolteachers had no significant different scores on all subscales of the DASS-21 and the respective effect sizes were also very small (Cohen's $d$ was between 0.01 to 0.02 ). As such, it was appropriate to pool primary and middle schoolteachers for further analyses.

Subsequently, the participants were divided into three groups: teachers engaging in online teaching, teachers not engaging in online teaching, and their respective students. The descriptive statistics (i.e., means [and SDs] or frequencies [percentages]) and significance tests were used to compare the differences among the demographic variables (i.e., gender and school type), and the degree of the observed scores in the two instruments (i.e., FCV-19S and DASS-21) among the three groups.

To answer RQ1, the following tests were conducted: internal reliability was evaluated using McDonald's $\omega$ (Trizano-Hermosilla \& Alvarado, 2016) for the separated groups because the assumption of tau-equivalence was violated (i.e., the robust $F$ was from 29.07 to $136.07, p<0.001$ ), which indicates using Cronbach's $\alpha$ was inappropriate; confirmatory factor analysis (CFA) and structural equation modeling (SEM) were used to assess the construct validity and concurrent validity (i.e., the extent of the relationship between the latent variables of the FCV-19S and DASS-21), respectively. LISREL 8.80 was used with diagonally weighted least squares (DWLS) for parameter estimation because DWLS is more appropriate for estimating non-normally distributed data ( $\mathrm{Li}, 2016)$. A multi-group analysis was used to test whether the measurement invariance of FCV-19S was supported across the three groups.

Given that construct validity needs to be grounded by multiple types of evidence, the specific procedure was as follows. To examine construct validity, the tests of factorial validity, convergent validity, and discriminant validity were conducted in sequence. For factorial validity, previous studies (Bitan et al., 2020; Caycho-Rodríguez et al., 2021b; Chi et al., 2021; Huarcaya-Victoria et al., 2020; Masuyama et al., 2020; Soraci et al., 2020) proposed three types of factor structures for testing the factorial validity of FCV-19S. The factor structures were a one-factor model (general factor of fear of COVID-19), a two-factor model (Items 1, 2, 4 and 5 belonged to emotional fear reactions and Items 3, 6 and 7 belonged to somatic expressions), and a bifactor model. According to Hair et al. (2019), to provide evidence of convergent and discriminant validity in CFA, psychometricians need to examine (i) whether the items that are indicators of a specific construct converge or share a high proportion of variance in common, and (ii) the extent to which a construct is truly distinct from other constructs. With CFA, the composite reliability (CR) and average variance extracted (AVE) are the most common ways to assess convergent and discriminant validity (Fornell \& Larcker, 1981; Hair et al., 2019; Kaartina et al., 2015; Netemeyer et al., 2003).

In terms of the criterion for evaluating factorial and concurrent validity, the following combined indices were adopted: chi-square, comparative fit index (CFI), non-normed fit index (NNFI), root mean square error of approximation (RMSEA), and standardized root mean square residual (SRMR). RMSEA values of 0.06 or lower, SRMR values of 0.08 or lower, CFI values of 0.95 or higher, and NNFI values of 0.95 or higher are considered acceptable (Hu \& Bentler, 1999). To test whether convergent and discrimant validity was supported, CR> 0.70 and AVE $>0.50$ for each construct is required (Fornell \& Larcker, 1981; Hair et al., 2019; Kaartina et al., 2015). Moreover, the square root of AVE should exceed the correlations between the latent variables making each pair to support discriminant validity (Fornell \& Larcker, 1981; Hair et al., 2019; Netemeyer et al., 2003). For the bifactor model, the aforementioned model fit indices were not appropriate to use due to "overfitting" (Bonifay et al., 2017). As such, explained common variance (ECV), percentage of uncontaminated correlations (PUC), and Omega-hierarchical $(\mathrm{OH})$ were used to justify if the raw scores can be seen as univocal indicators of the general factor and specify if the measurement model was unidimensional or multidimensional (Arrindell et al., 2017; Rodriguez et al., 2016). If the general factor of $\mathrm{OH}$ is higher than 0.80 , the variance of the total scores can be attributed to a single general factor. If both ECV and PUC $>0.70$, the relative bias will be slight and the measurement model can be essentially judged uni-dimensional (Rodriguez et al., 2016).

$\triangle \mathrm{CFI}, \triangle \mathrm{RMSEA}$, and $\triangle \mathrm{SRMR}$ were used to examine whether measurement invariance was supported across three groups. Given that the number of participants in the three groups was very different in the present study (i.e., Group 1: Teachers using online teaching $=9150$, Group 2: Teachers not using online teaching $=1984$, and Group 3: Students=4335), and imbalanced groups may lead to incorrect conclusions of invariance, Yoon and Lai's (2018) subsampling method was utilized to address the imbalanced sample size issue. More specifically, analysis involved 100 random sampling replications from the larger group and each random sample was used for conducting measurement invariance analysis along with the original sample in the smaller group. Therefore, the measurement invariance analysis was carried out 100 times. The mean 
of each fit statistic across the 100 replications was calculated and if the mean value falls within the range of good fit, the measurement invariance of FCV-19S is supported. With 100 replications, the mean statistics value in configural model (i.e., baseline model) was compared with the factor-loading constrained model; the mean statistic value in the factor-loading-constrained model (a less constrained model) was compared with the factor-loading and itemintercept constrained model (a more constrained model). If $\Delta$ CFI $>-0.01, \Delta$ RMSEA $<0.015$, and $\Delta$ SRMR $<0.03$ (for factor loading) or $<0.01$ (for item intercept), the two nested models are seen equivalent and therefore the measurement invariance is supported (Chen, 2007).

To answer RQ2, a multilevel analysis, intercept as outcome model (Dickinson \& Basu, 2005), with HLM 6.0 was used to test the association between the fear of COVID-19 perceived by the student and the corresponding home-room teachers. Similarly, the same way was adopted to analyze the possible association between psychological distress among students and their respective home-room teachers. In this hierarchical linear model, the variables of gender (including students and the homeroom teachers) and teachers' working years were included as control variables.

Student-level: Fear of COVID $-19 \mathrm{ij}=\beta 0 \mathrm{j}+\beta 1 \mathrm{j}$ (Gende rij) $+\gamma \mathrm{ij}$

Teacher level: $\beta 0 \mathrm{j}=\gamma 00+\gamma 01$ (Gender $\mathrm{j}$ ) $+\gamma 02$ (Working years $\mathrm{j})+\gamma 03($ Fear of COVID $-19 \mathrm{j})+\mathrm{U} 0 \mathrm{j} ; \beta 1 \mathrm{j}=\gamma 10$

Student-level: Psychological distressij $=\beta 0 \mathrm{j}+\beta 1 \mathrm{j}($ Gender ij $)+\gamma \mathrm{ij}$

Teacher level: $\beta 0 \mathrm{j}=\gamma 00+\gamma 01$ (Gender $\mathrm{j}$ ) $+\gamma 02$ (Working years $\mathrm{j})+\gamma 03$ (Psychological distress $\mathrm{j}$ ) $+\mathrm{U} 0 \mathrm{j} ; \beta 1 \mathrm{j}=\gamma 10$

\section{Results}

\section{The descriptive and the difference between two kinds of teachers and students}

The findings concerning demographic variables and descriptive statistics are provided in Table 1. The results showed that teachers (including those who had or had not engaged in online teaching during school closure) were more from primary schools (engaging in online teaching $=63.9 \%$; not engaging in online teaching $=54.6 \%$ ) and most students were from middle schools (90.2\%). Moreover, the observed score of anxiety in DASS-21 was significantly higher among teachers engaging in online teaching than students $\left(F_{(2,15466)}=5.59, p=.003\right)$. Regarding the FCV-19S, students had a significantly higher level than teachers on every item $\left(F_{(2,15466)}\right.$ was from 15.79 to 217.65 , all $p$-values $\left.<.001\right)$.

\section{Psychometrics properties}

The internal reliability of FCV-19S among teachers and students was very good to excellent. The overall McDonald's $\omega$ was ranged from 0.90 to 0.91 . The results of the factorial validity indicated that one-factor structure did not fit well among the two types of teachers and students because of the high RMSEA ( 0.126 for teachers engaging in online teaching; 0.122 for teachers not engaging in online teaching; 0.086 for students). Referring to the modification index, factor structure, and other empirical works, the estimation of the correlated measurement error was sequentially added one by one. Consequently, the fit of the revised one-factor

Table 1 Descriptive statistics and difference comparisons between three groups

\begin{tabular}{|c|c|c|c|c|c|}
\hline & \multicolumn{3}{|l|}{$\mathrm{M}(\mathrm{SD})$ or $\mathrm{n}(\%)$} & \multirow[t]{2}{*}{ F or $\chi^{2}(p$-value $)$} & \multirow[t]{2}{*}{ Post-hoc } \\
\hline & $\begin{array}{l}\text { 1. Teachers using } \\
\text { online teaching } \\
(n=9154)\end{array}$ & $\begin{array}{l}\text { 2. Teachers not using } \\
\text { online teaching } \\
(\mathrm{n}=1984)\end{array}$ & $\begin{array}{l}\text { 3. Students } \\
(\mathrm{n}=4335)\end{array}$ & & \\
\hline Gender (female) & $6625(72.4 \%)$ & $1294(65.2 \%)$ & $1993(46.0 \%)$ & $893.92(<.001)$ & \\
\hline School type (primary school) & $5850(63.9 \%)$ & $1083(54.6 \%)$ & $425(9.8 \%)$ & $3500.66(<.001)$ & \\
\hline DASS-21total score & $0.36(0.48)$ & $0.36(0.49)$ & $0.36(0.49)$ & $0.15(.858)$ & -- \\
\hline Depression subscale score & $0.31(0.48)$ & $0.33(0.51)$ & $0.33(0.53)$ & $1.66(.191)$ & -- \\
\hline Anxiety subscale score & $0.34(0.48)$ & $0.35(0.50)$ & $0.32(0.49)$ & $5.59(.004)$ & $3>1,3>2$ \\
\hline Stress subscale score & $0.42(0.51)$ & $0.42(0.53)$ & $0.44(0.53)$ & $2.93(.053)$ & -- \\
\hline FCV-19S & $2.68(0.75)$ & $2.66(0.77)$ & $2.90(0.78)$ & $129.40(<.001)$ & $3>1,3>2$ \\
\hline Item 1 & $3.17(1.01)$ & $3.11(1.04)$ & $3.25(1.03)$ & $15.79(<.001)$ & $3>1>2$ \\
\hline Item 2 & $3.02(0.97)$ & $2.98(0.98)$ & $3.16(1.03)$ & $37.90(<.001)$ & $3>1,3>2$ \\
\hline Item 3 & $2.20(0.86)$ & $2.20(0.87)$ & $2.53(0.94)$ & $217.65(<.001)$ & $3>1,3>2$ \\
\hline Item 4 & $2.85(1.03)$ & $2.82(1.03)$ & $3.04(1.07)$ & $55.35(<.001)$ & $3>1,3>2$ \\
\hline Item 5 & $2.80(0.97)$ & $2.75(0.98)$ & $3.13(0.99)$ & $186.66(<.001)$ & $3>1>2$ \\
\hline Item 6 & $2.27(0.86)$ & $2.27(0.88)$ & $2.47(0.91)$ & $77.45(<.001)$ & $3>1,3>2$ \\
\hline Item 7 & $2.49(0.96)$ & $2.47(0.94)$ & $2.71(0.97)$ & $90.31(<.001)$ & $3>1,3>2$ \\
\hline
\end{tabular}

DASS-21 = Depression, Anxiety, Stress Scale 21; FCV-19S = Fear of COVID-19 Scale 
Table 2 Testing factor structures of the Fear of COVID-19 Scale (FCV-19S)

\begin{tabular}{|c|c|c|c|c|c|}
\hline & $\chi^{2}(d f)$ & $C F I$ & $N N F I$ & RMSEA & $S R M R$ \\
\hline \multicolumn{6}{|l|}{ One-factor model } \\
\hline Students & $463.76(14)$ & 0.989 & 0.984 & 0.086 & 0.041 \\
\hline Students ${ }^{a}$ & $167.76(11)$ & 0.996 & 0.993 & 0.058 & 0.023 \\
\hline Teachers using online teaching & $2062.46(14)$ & 0.975 & 0.962 & 0.126 & 0.065 \\
\hline Teachers using online teaching ${ }^{a}$ & $607.10(11)$ & 0.993 & 0.986 & 0.077 & 0.038 \\
\hline Teachers not using online teaching & $429.07(14)$ & 0.978 & 0.968 & 0.122 & 0.061 \\
\hline Teachers not using online teaching ${ }^{\text {a }}$ & $95.89(11)$ & 0.996 & 0.992 & 0.062 & 0.031 \\
\hline \multicolumn{6}{|l|}{ Two-factor model } \\
\hline Students & $243.26(13)$ & 0.994 & 0.991 & 0.065 & 0.029 \\
\hline Students ${ }^{a}$ & $127.33(10)$ & 0.997 & 0.994 & 0.052 & 0.018 \\
\hline Teachers using online teaching & $636.20(13)$ & 0.992 & 0.988 & 0.072 & 0.041 \\
\hline Teachers using online teaching ${ }^{\text {a }}$ & $275.25(10)$ & 0.997 & 0.993 & 0.054 & 0.020 \\
\hline Teachers not using online teaching & $140.49(13)$ & 0.993 & 0.989 & 0.070 & 0.039 \\
\hline Teachers not using online teaching ${ }^{a}$ & $31.81(10)$ & 0.999 & 0.998 & 0.033 & 0.014 \\
\hline \multicolumn{6}{|l|}{ Bifactor model } \\
\hline Students & $82.49(7)$ & 0.998 & 0.995 & 0.049 & 0.016 \\
\hline Students ${ }^{a}$ & $72.46(4)$ & 0.998 & 0.991 & 0.062 & 0.016 \\
\hline Teachers using online teaching & $118.15(7)$ & 0.996 & 0.999 & 0.042 & 0.011 \\
\hline Teachers using online teaching ${ }^{a}$ & $96.99(4)$ & 0.999 & 0.994 & 0.050 & 0.011 \\
\hline Teachers not using online teaching & $16.31(7)$ & 0.999 & 0.999 & 0.026 & 0.008 \\
\hline Teachers not using online teaching ${ }^{a}$ & $13.14(4)$ & 0.999 & 0.998 & 0.034 & 0.008 \\
\hline
\end{tabular}

$\mathrm{CFI}=$ comparative fit index; NNFI = non-normed fit index; RMSEA = root mean square error of approximation; SRMR = standardized root mean square residual.

atem uniqueness was corelated for the following pairs: Items 1 and 2; Items 1 and 4; Items 6 and 7. model was generally acceptable among three groups (see Table 2), after adding the correlated measurement errors in Items 1 with 2 both from the factor of emotional fear reactions (also added in Alyami et al., 2020; Gozpinar et al., 2021; Han et al., 2021; Iversen et al., 2021); Items 1 with 4 both from the factor of emotional fear reactions (also added in Cavalheiro \& Sticca, 2020; Iversen et al., 2021; Wakashima et al., 2020); and Items 6 with 7 both from the factor of somatic expressions (also added in Alyami et al., 2020; Gozpinar et al., 2021; Iversen et al., 2021). CR and AVE in the revised one-factor model was 0.63 and 0.92 for teachers engaging in online teaching; 0.65 and 0.93 for teachers not engaging in online teaching; 0.66 and 0.93 for students. Given that CR and AVE across three groups met the criterion, the convergent validity was supported in the revised one-factor model.

The internal reliability of the two-factor model was also very good. McDonald's $\omega$ ranged from 0.85 to 0.87 on the factors of emotional fear reactions and somatic expressions among the three groups. Moreover, the two-factor structure had excellent fit among all groups (CFI was from 0.992 to 0.997; NNFI was from 0.988 to 0.991; RMSEA was from 0.065 to 0.072 ; SRMR was from 0.029 to 0.041 ). After adding the aforementioned correlated measurement errors (i.e., Items 1 with 2; Items 1 with 4; and Items 6 with 7), the model fit also improved (CFI was from 0.997 to 0.997; NNFI was from 0.988 to 0.991 ; RMSEA was from 0.065 to 0.072; SRMR was from 0.029 to 0.041). CR and AVE was calculated based on the factor loading in the revised model, indicating a high convergent validity between the two factors among the three groups. More specifically, AVE and $\mathrm{CR}$ of emotional fear reactions was 0.63 and 0.87 , respectively, for teachers engaging in online teaching; 0.65 and 0.88 for teachers not engaging in online teaching; and 0.63 and 0.87 for students. AVE and CR of somatic expressions was 0.76 and 0.91 , respectively, for teachers engaging in online teaching; 0.78 and 0.91 for teachers not engaging in online teaching; and 0.75 and 0.90 for students. However, the high correlation of the two factors constituted to the poor discriminatory validity since the square root of AVE of the factor was lower than the inter-latent factors correlations (see Table 3).

The results of the bifactor model showed that the raw scores in FCV-19S can be attributed to a general factor since $\mathrm{OH}$ of the general factor was 0.96 for teachers engaging in online teaching, 0.94 for teachers not engaging in online teaching, and 0.92 for students. However, regarding the measurement model, it is hard to conclude that FCV-19S 
Table 3 Results of convergent and discriminant validity analysis in the Fear of COVID-19 Scale (FCV-19S)

$\begin{array}{ll}\begin{array}{l}\text { Emotional fear } \\ \text { reactions }\end{array} & \begin{array}{l}\text { Somatic } \\ \text { expres- } \\ \text { sions }\end{array}\end{array}$

Teachers using online teaching

Emotional fear reactions

0.794

Somatic expressions

0.873

0.871

Teachers not using online teaching

Emotional fear reactions

Somatic expressions

0.806

0.890

Students

Emotional fear reactions

0.794

Somatic expressions

0.948

0.866

Diagonal elements in bold are square root of averaged variance extracted. When these values were higher than the inter-latent factors correlations (off-diagonal elements), the discriminant validity was support for the respective latent variable.

Emotional fear reactions =Items 1, 2, 4 and 5 in the FCV-19S.

Somatic expressions $=$ Items 3, 6 and 7 in the FCV-19S.

was unidimensional, given that ECV was below 0.70 among the three groups (teachers engaging in online teaching $=$ 0.53 , teachers not engaging in online teaching $=0.56$, and students $=0.59$ ). The PUC was 0.57 among the three groups.

Regarding the concurrent validity of FCV-19S with psychological distress (and following the results of the aforementioned factorial validity), the factor structure adding three-pair correlations with measurement error in the FCV$19 \mathrm{~S}$ was used. Furthermore, although better model fit was found on the two-factor structure, the one-factor structure is also possible since a high value of $\mathrm{OH}$ was found in the bifactor model. As such, one and two-factor structure were both included in the analysis. The results indicated that the one-factor model (Fig. 1) and the two-factor model (Fig. 2) had acceptable fit among the three groups (one-factor model: CFI was from 0.996 to 0.999 ; NNFI was from 0.995 to 0.999; RMSEA was from 0.011 to 0.039 , and SRMR was from 0.036 to 0.053 ; two-factor model: CFI was from 0.997 to 0.999 ; NNFI was from 0.995 to 0.999 ; RMSEA was from 0.001 to 0.037 , and SRMR was from 0.020 to 0.028 ). Moreover, the coefficients between latent variables were generally significant. More specifically, in the one-factor model, the coefficient of the general factor with psychological distress was significant among all three groups (teachers engaging in online teaching: coefficient $=0.39, t=14.14, p<0.001$; teachers not engaging in online teaching: coefficient $=$ $0.40, t=4.61, p<0.001$; students: coefficient $=0.25, t=8.66$, $p<0.001)$. In the two-factor model, except for the group of teachers not using online teaching, the coefficient of the factor of somatic expressions was significantly related with psychological distress among the other two groups (teachers engaging in online teaching: coefficient $=0.67, t=4.50$, $p<0.001$; students: coefficient $=0.63, t=2.05, p=0.02$ ), while the factor of emotional fear in the two-factor model was not relevant with the criterion variable among all three groups. It is clear that the somatic expressions factor contributed more influence on individuals' psychological distress. Finally, the difference between the results with and without adding three-pair correlations with measurement errors was evaluated and no obvious difference was found that the aforementioned conclusions of the significant test did not substantially change (i.e., only the path coefficient between FCV-19S with

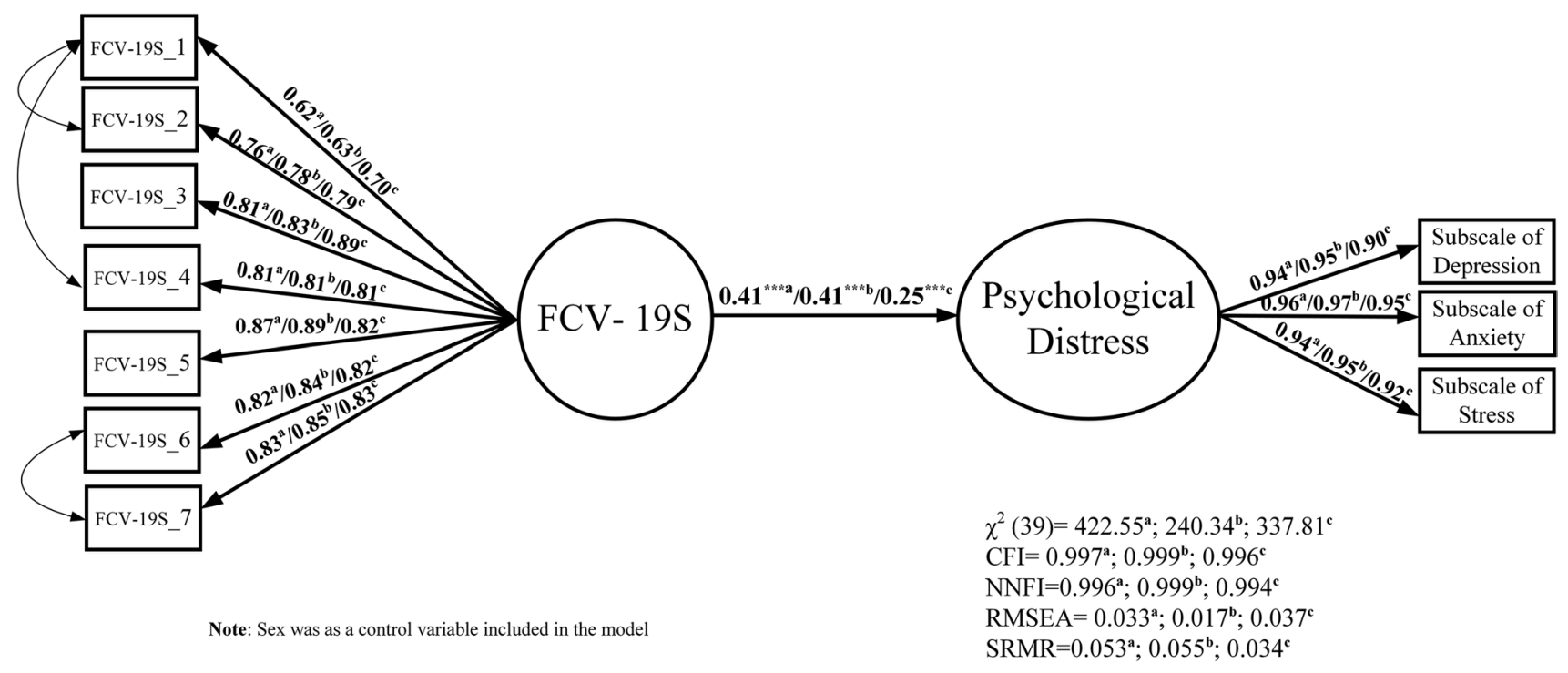

Fig. 1 The concurrent validity of the one-factor structure FCV-19S supported by the association with psychological distress. a The association coefficient of teachers engaging in online teaching; b The association coefficient of teachers not engaging in online teaching; $\mathbf{c}$ The association coefficient of students 


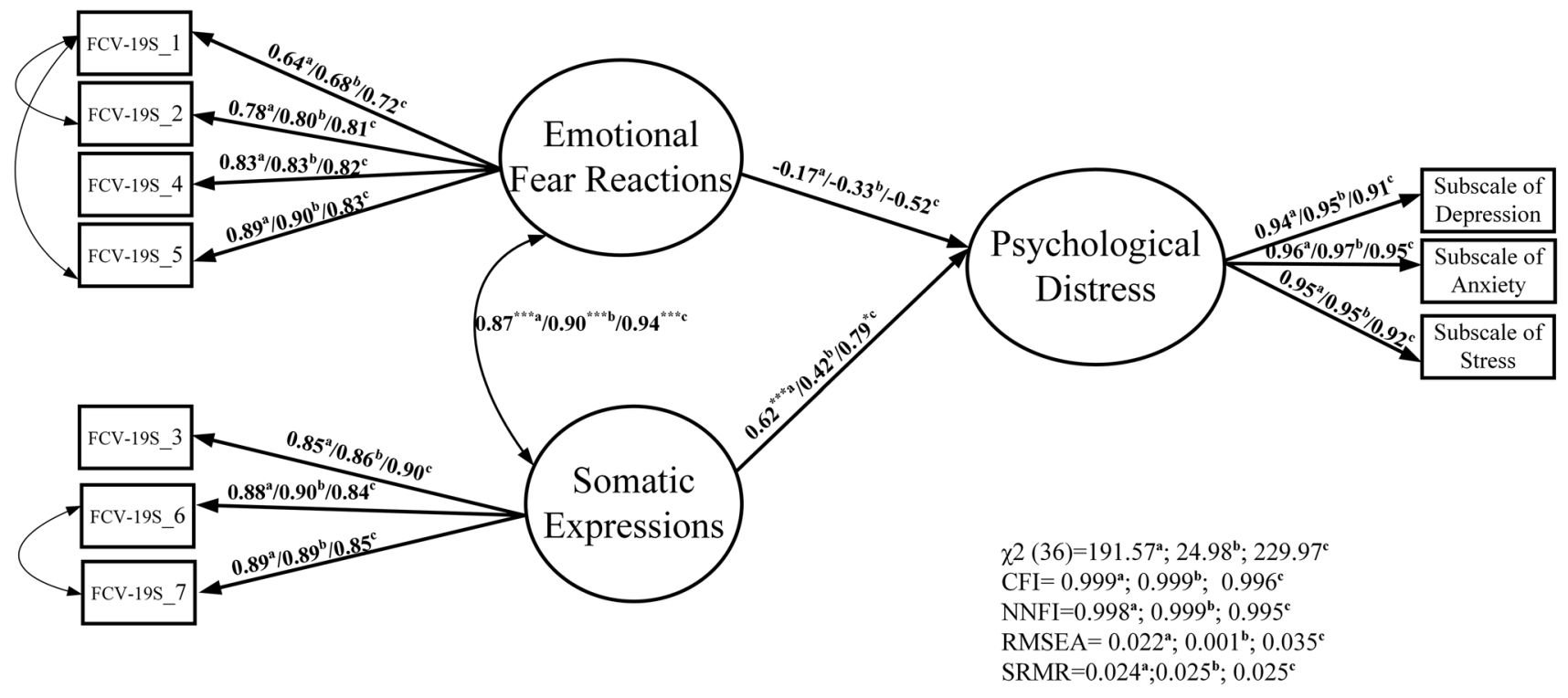

Note: Sex was as a control variable included in the model

Fig. 2 The concurrent validity of the two-factor structure FCV-19S supported by the association with psychological distress. a The association coefficient of teachers engaging in online teaching; $b$ The association coefficient of teachers not engaging in online teaching; c The association coefficient of students

was multidimensional. The results indicated that FCV19S had measurement invariance at factor loadings across each pair-group while not at item thresholds. That is, the items' intercepts were not the same across three compared groups (see Table 4). invariance because the bifactor model suggested FCV-19S

criterion variable changed slightly). Overall, the concurrent validity of the FCV-19S was supported across the three groups when treating the FCV-19S as a general factor.

In terms of measurement invariance, the two-factor structure was used to conduct the test of measurement
Table 4 Means of Fit Indexes in Measurement invariance Using the Subsampling Method across three groups (i.e., teachers using online teaching, teachers not using online teaching, and students).

\begin{tabular}{|c|c|c|c|}
\hline & Configural Model & $\begin{array}{l}\text { Loadings Constrained } \\
\text { as Equal }\end{array}$ & $\begin{array}{l}\text { Loadings and Thresh- } \\
\text { olds Constrained as } \\
\text { Equal }\end{array}$ \\
\hline \multicolumn{4}{|c|}{ Students and teachers using online teaching } \\
\hline$X^{2}(d f)$ or $\Delta X^{2}(\Delta d f)$ & $276.91(20)$ & $168.57(5)$ & $457.88(5)$ \\
\hline$C F I$ or $\triangle C F I$ & 0.997 & -0.002 & -0.004 \\
\hline$R M S E A$ or $\triangle R M S E A$ & 0.029 & 0.009 & 0.040 \\
\hline$S R M R$ or $\triangle S R M R$ & 0.032 & 0.011 & $-\mathbf{0 . 0 3 8}$ \\
\hline \multicolumn{4}{|c|}{ Students and teachers not using online teaching } \\
\hline$X^{2}(d f)$ or $\Delta X^{2}(\Delta d f)$ & $107.21(20)$ & $187.58(5)$ & $2301.72(5)$ \\
\hline$C F I$ or $\triangle C F I$ & 0.998 & -0.005 & -0.022 \\
\hline$R M S E A$ or $\triangle R M S E A$ & 0.018 & 0.014 & 0.058 \\
\hline$S R M R$ or $\triangle S R M R$ & 0.021 & 0.021 & -0.028 \\
\hline \multicolumn{4}{|c|}{ Teacher using and not using online teaching } \\
\hline$X^{2}(d f)$ or $\Delta X^{2}(\Delta d f)$ & $85.53(20)$ & $14.04(5)$ & $400.21(5)$ \\
\hline$C F I$ or $\triangle C F I$ & 0.996 & 0.001 & -0.025 \\
\hline$R M S E A$ or $\triangle R M S E A$ & 0.021 & -0.003 & 0.041 \\
\hline$S R M R$ or $\triangle S R M R$ & 0.021 & 0.001 & 0.015 \\
\hline
\end{tabular}

$\mathrm{CFI}=$ comparative fit index; RMSEA = root mean square error of approximation; SRMR = standardized root mean square residual. the bold value indicates invariance; i.e., $\Delta \mathrm{CFI}>-0.01 ; \Delta \mathrm{RMSEA}<0.015$; $\Delta \mathrm{SRMR}<0.03$ (for factor loading) or $<0.01$ (for item intercept) 


\section{The association of perceived fear and psychology distress between students and the respective home-room teachers}

In the multilevel analysis, after matching the home-room teachers and their students, 71 teachers and 3,218 students were under the analysis after eliminating missing responses in the pair identity. The results showed that in the condition of adding the control variables (i.e., gender and teachers' working years), home-room teachers' psychological distress was significantly positive with their respective students $(\beta=$ 0.25 , $\mathrm{t}$-ratio $=2.34, p=0.02$ ). However, there was no significant association of fear of COVID-19 between home-room teachers' and students. Moreover, the residual variance in $\beta_{0 \mathrm{j}}$ was still significant $\left(\chi^{2}=101.75, p=0.004\right)$ on students' psychological distress and on fear of COVID-19 $\left(\chi^{2}=98.99\right.$, $p=0.007)$ indicating that there were other teacher-level variables that affect students' psychological distress and the fear of COVID-19.

\section{Discussion}

This present study comprised a large-scale cross-sectional survey which evaluated the psychometric properties of the Chinese FCV-19S among specific populations (i.e., schoolteachers and their respective students from primary and middle schools). The association of the perceived fear of COVID-19 and psychological distress was also assessed between home-room teachers and their students. The results demonstrated that the FCV-19S with good internal reliability had an ideal factorial validity with a two-factor structure among schoolteachers and student groups. Moreover, the revised one-factor structure was also acceptable after adding the estimation of three-pair items' correlated measurement errors. Furthermore, the convergent validity was acceptable for both one and two-factor structures, while the discriminatory validity was not supported among three groups due to the high correlations between the two latent sub-factors. The sub-factors of emotional fear reactions and somatic expressions are not easy to distinguish, probably because there is a common general factor that is dominant (this evidence is supported by the bifactor model results). The results of the bifactor model indicated that although most of the raw scores can be attributed to the general factor, the structure of the FCV-19S was multidimensional across three groups. The concurrent validity of the FCV-19S was supported given that the overall score had a close association with psychological distress across the three groups in the one-factor structure. The measurement invariance further showed that the FCV19S had measurement invariance with factor loadings but not at item thresholds. More specifically, teachers engaging in online teaching, teachers not engaging in online teaching, and students interpreted the items of FCV-19S in different ways resulting in unequal responses across the three groups. In addition, psychological distress but not perception of fear of COVID-19 between home-room teachers and their students was significant associated.

The original one-factor structure did not fit well among the two types of teacher and students due to the unacceptable RMSEA, and this result is consistent with some studies reporting a unsatisfactory RMSEA (Alyami et al., 2020; Cavalheiro \& Sticca, 2020; Caycho-Rodríguez et al., 2021a; Chi et al., 2021; Gozpinar et al., 2021; Huarcaya-Victoria et al., 2020; Masuyama et al., 2020; Wakashima et al., 2020; Winter et al., 2020). In Alyami et al. (2020)'s study, they found that there were high covariances between Items 3 , 6, and 7, which may possibly explain the unacceptable RMSEA in the present study. Chi et al. (2021) reported this high covariance between measurement errors and mentioned that these items shared specific commonalities which can indicate an independent factor (i.e., somatic expressions). In line with previous literature, the present study showed a high covariance between Items 6 and 7, indicating that the two-factor structure is more suitable in specifying the characteristic of the perceived fear of COVID-19 among teacher and student populations. This finding echoes the definition of fear that it is an aggregate state including subjective experience, emotional expression and physical response (Gross \& Feldman Barrett, 2011).

According to Table S1 based on the published psychometric studies of FCV-19S and the respective severity of the COVID-19 outbreak during the survey time in that country (or region), of the five studies in which the measurement error correlation was not added and the one-factor structure was supported, four studies had a confirmed deaths per million at the surveyed time less than 10 (i.e., Ahorsu et al., 2020; Chang et al., 2020; Mahmood et al., 2020; Sakib et al., 2020). Moreover, the confirmed cases in these four studies also belonged to the lower ones in the table. It is clear that one-factor structure was mostly supported in countries where the severity of COVID-19 was less. A possible explanation is that when individuals were not aware of the great impact of COVID-19 in their country, the somatic expressions factor, which is induced by strong feelings of fear, may be weak and may not be triggered. Interestingly, in a few countries, the one-factor-structure was not supported, even though confirmed cases and deaths were still not severe (e.g., in Table S1, New Zealand [Winter et al., 2020] and Japan [Masuyama et al., 2020; Wakashima et al., 2020]). This may be due to the fact that these countries took strict preventive measures before the pandemic became serious (Wakashima et al., 2020; Winter et al., 2020) and these actions may have deepened the fears of residents in those countries. On the other hand, the two-factor structure was usually supported in countries where the pandemic had already had huge 
influence on the residents. More specifically, among the five countries with higher death rates (i.e., confirmed deaths per million over 100), three are supported by the results of the two-factor structure (Caycho-Rodríguez et al., 2021b; Huarcaya-Victoria et al., 2020; Magano et al., 2021), and the other two were not tested for the two-factor structure (Soraci et al., 2020; Soares et al., 2021). As such, the structure of FCV-19S may be quite prominently affected by the severity of individual's perception of the pandemic.

Following this speculation, the present study's findings on teachers (i.e., the original one-factor structure did not fit among teachers engaging in online teaching during school closure) can be reasonably explained. This may be due to the fact that when schoolteachers have to use the internet for long periods of time because of their work (e.g., in Shen et al., 2020's survey in mainland China, the amount of time spent online required by teachers for their online teaching and preparation exceeded five hours per day during school closure), this population has a high level of fear of COVID19 and, therefore clearly knew the serious harm caused by the disease which may lead to somatic expressions. More specifically, just like individuals who used the internet and/ or social media more often during COVID-19 outbreak noted in the literature (Gao et al., 2020; Ogbodo et al., 2020; Rodríguez-Hidalgo et al., 2020), teachers are likely to have received a lot information concerning COVID-19 through social media. This is likely to increase their fear level based on Li's (2021) longitudinal finding that the more frequent exposure to COVID-19 news an individual has, the higher fear of COVID-19. Moreover, teachers with a high uncertainty regarding their teaching schedule (Eşici et al., 2021; Khanal et al., 2021; Kim \& Asbury, 2020; Kulikowski et al., 2021; Lepp et al., 2021; MacIntyre et al., 2020) may actively search for pandemic-related information. Previous studies have also reported that active information-seeking behaviors also increase people's fear (Dillard et al., 2020; Huang et al., 2020; Ogbodo et al., 2020; Superio et al., 2021).

Using the same version of FCV-19S, Chi et al. (2021) conducted a study among the general adult population in mainland China at a similar time during the pandemic as the present study (i.e., May to June, 2020), but teachers in the present study had higher degrees of fear on almost every item in FCV-19S, except for Item 4 compared to Chi et al.'s study. (The sum observed score of FCV-19S in Chi et al.'s study was $16.50[\mathrm{SD}=5.55]$; whereas in the present study it was 18.78 [ $\mathrm{SD}=5.23]$ among teachers engaging in online teaching, and $18.60[\mathrm{SD}=5.36]$ among teachers not engaging in online teaching). Furthermore, compared to patients with mental health illness in Taiwan (Chang et al., 2020) whose confirmed cases and deaths in the country were as low as those during the present study (see Table S1), the teachers in this present study also had an overall higher degree of fear, except for the items belonging to somatic expressions. (In the emotional fear reactions factor, for patients with mental health illness it was 11.31 [SD=5.11] whereas for teachers engaging in online teaching it was 11.84 [ $\mathrm{SD}=3.33$ ], and for teachers not engaging in online teaching it was 11.66 [SD=3.40]).

It is understandable that individuals with mental health illnesses are more concerned about COVID-19 in terms of physical aspects. However, in relation to emotional fear reactions, teachers are higher than patients with mental health illness. This fully shows that teachers' fears are extremely high. As such, these comparisons confirm that teachers are one of the more vulnerable groups of developing mental health illness during COVID-19 outbreak (Aperribai et al., 2020; Li et al., 2020). The findings of the present study are also in line with those of Mari et al. (2021) who surveyed other occuptations (i.e., practitioners and managers). Teachers in the study had the highest score on the item "The coronavirus is a mysterious and highly deadly virus capable of decimating the world's population", reflecting the highest fear level of COVID-19.

Further differences in the results between the two types of teachers in the present study should also be noted. The two kinds of teachers had similar results in terms of the degree of observed scores (as aforementioned) and the test of factorial validity (both groups had unsatisfactory model fit in the one-factor structure) because both types of teachers spent extra time for online teaching. However, there were two substantial differences between them. In the concurrent validity adopting the two-factor structure, the significant association between factor of somatic expressions and psychological distress was only found among teachers engaging in online teaching but not those engaging in non-online teaching. Moreover, in the measurement invariance test, these two types of teachers had different perceptions on the item wordings of the FCV-19S. A lot of literature has noted that during school closures, teachers not only needed to conduct online teaching but also spent a lot of time communicating with stakeholders (Kaden, 2020; Khanal et al., 2021; Kim et al., 2020; Nilson \& Goodson, 2021). Similarly, it could be that the teachers in the present study who were not conducting online classes (mostly gym class, music class, or art class) still needed to use the internet for work. However, it is not known how much time a week was spent on the internet for school work or what the specific work involved as this was not investigated. However, in the case of the association between somatic expression factor with psychological distress and the differences in the interpretation of the item wording of FCV-19S between the two types of teachers, the amount of time spent on the internet may still be the main reason for the aforementioned differences between the two kinds of teachers.

Regarding the results of the bifactor model, the findings here echo Caycho-Rodríguez et al.'s (2021b) argument that 
the main variance of FCV-19S can be attributed to a general factor while also considering the fear of COVID-19 to be a multidimensional construct. More specifically, the results in the present study confirmed the raw scores in FCV-19S can represent a general fear of the pandemic and also differentiate the meaning of the two subscales among teachers and students. Despite the bifactor model being methodologically controversial in terms of the symptom of overfitting (Bonifay et al., 2017), due to the very high value of $\mathrm{OH}$ among schoolteachers and students, the present study's results suggest that the scores of FCV-19S can be used as a unidimensional construct, which has been already been adopted in previous studies (e.g., Lin et al., 2020). On the other hand, FCV-19S should also be treated as multidimensional when clinical consulting practitioners want to design interventions more specifically targeting the ingredients of fear towards COVID- 19.

Apart from the consideration of schoolteachers' high level of COVID-19 fear, our results on primary and middle school students also reminds healthcare providers should pay additional attention to somatic expressions factor for this population since our result was more support by the perspective that students' cognitions are still immature and are therefore easily affected by detrimental news as a consequence of COVID-19 (Chi et al., 2021). This result is consistent with Chi et al. (2021) where those aged under 18 years had significantly higher scores on FCV-19S than adults. Moreover, referring to Table S1, including this present study and other studies with students aged under 18 years (Gozpinar et al., 2021; Masuyama et al., 2020), the observed scores of FCV-19S among children and adolescents were mostly higher than adults. Therefore, more monitoring and guidance is required during this period time compared with college and university students. Such comparisons can provide valuable empirical evidence concerning the use of the FCV-19S in the school context.

In terms of the association of the fear of COVID-19 and the psychological distress between home-room teachers and the respective students, only psychological distress (and not COVID-19 fear) was found to be significantly correlated. Given that emotion is contagious (Wild et al., 2001) and students' development is influenced by the intensive interaction with teachers (especially for home-room teachers) in the school microsystem (Bronfenbrenner, 1992; Neal \& Neal, 2013), both fear and mental health illness were hypothesized to be associated between students and teachers. However, this hypothesis was not fully supported, and the present preliminary findings showed that psychological distress among teachers and their students was significantly associated, even in the online environment. Moreover, since the residual variance was still significant on students' psychological distress and on fear of COVID-19, the explanatory variables at teacher-level can be further explored in future research.

The contribution of the present study is threefold. First, the study utilized a large-scale cross-sectional survey, which is quite rare in the research in the school context response to COVID-19. For example, the large sample size provides a more solid evidence base when evaluating the mixed results of the difference between those aged under 18 years and adults in the general population utilizing relatively small samples (e.g., Midorikawa et al., 2021; Wakashima et al., 2020). Moreover, there were very few empirical studies investigating fear of COVID-19 among schoolteachers (Khanal et al.,). Second, to the best of the present authors' knowledge, this is the first study to apply the FCV-19S to schoolteachers. Utilizing the same version of FCV-19S, the present finding indicated that teachers had a higher degree of fear of COVID-19 than adults from the general population in Mainland China (Chi et al., 2021) and patients with mental health illness in Taiwan (Chang et al., 2020). This finding highlights the need to investigate how online teaching adopted in a hurried way affects teachers' mental health. Third, the multilevel analysis results showed that psychological distress appears to be transferred across different levels although the fear of COVID-19 was not directly related between teachers and students.

Although there was no significant association of fear of COVID-19 between students and home-room teachers, this construct may still play another role. For example, it might be possible teachers' fear of COVID-19 moderates the relationship between students' fear of COVID-19 and students' psychological distress (or other dependent variables). Moreover, given that only a few control variables were in the model, it is also possible that some key confounding variables should be placed in the model (so we use the term partial out the confounding effect). Removing other confounding variables would show the real influence of the fear of COVID-19 from teacher level to student level, and more multilevel analysis is needed to investigate the mechanism of how these negative emotions spread out between teachers and students in online environments during school closure. This would broaden the scope of the single-level studies discussing the relationship between fear of COVID-19 and general psychological distress (for example, Lin et al., 2020 proposed a model to explain the relationship between fear of COVID-19 and mental health illness).

\section{Limitations}

The present study has four major limitations. First, the actual amount of time spent on the internet was not assessed during the school closure period. Therefore, it is hard to explain why the result is not in line with the hypothesis that there 
would be differences in the observed scores concerning the fear of COVID-19 (as well as mental health illness) and the psychometric properties of FCV-19S between two types of teachers (engaging in and not engaging in online teaching). Second, the present study utilized non-probability sampling. Therefore (and despite the large sample size), the generalizability of the present findings is restricted. Third, all the data were self-report and therefore subject to established methods biases. Finally, the sample in the multilevel analysis for RQ2 was more restricted compared with RQ1 analysis. The teacher sample in RQ2 was only collected from few schools (in one province) whereas the sample used to evaluate RQ1 was from more schools in three provinces. This restriction may lower the external validity of the present study.

\section{Conclusion}

At the time of writing (i.e., September 2021), COVID-19 still remains a global pandemic, with several countries in Asia declaring national closures again (Loong, 2021; Voice of America News, 2021; WHO, 2021c), and individuals' fear of COVID-19 remains. In this situation, a valid and robust tool to assess the fear of COVID-19 on potentially vulnerable groups is helpful. The present study found that FCV$19 \mathrm{~S}$ has very good psychometric properties among teachers and students from primary and middle schools. The raw scores in the scale can be explained by the general factor. Moreover, for the population with high pandemic fears (e.g., the students in this study), the subscale scores of perceived fear of somatic expressions factor can be used alone. In an environment where schools are closed during the pandemic, the psychological distress of teachers and students may still affect each other in online environments but the main mechanism may not be through the influence of fear.

Supplementary Information The online version contains supplementary material available at https://doi.org/10.1007/s12144-021-02471-3.

Acknowledgements This study was supported by grants from "Shandong Provincial Education Science Thirteenth Five-Year Plan 2019: Research on Classification Management and Evaluation of Higher Education Institutions in Shandong Province (VZ2019003)" and "National Social Science Foundation of China 2021 General Subject of Education "Research on Mixed Ownership Model of Vocational Education" (BJA210105).

Data availability statement The datasets generated during and/or analyzed during the current study are available from the corresponding author on reasonable request. Moreover, the materials and syntax files are available in the Open Science Framework via the following link: https://osf.io/h9wqx/?view_only=6b0bd75a46ca48a2b8229fa72f4d26 $2 \mathrm{e}$

\section{Declarations}

Conflict of interest All the authors declare that there is no conflict of interest.

\section{References}

Ahorsu, D. K., Lin, C.-Y., Imani, V., Saffari, M., Griffiths, M. D., \& Pakpour, A. H. (2020). The Fear of COVID-19 Scale: Development and initial validation. International Journal of Mental Health and Addiction, 1-9. Advance online publication. https:// doi.org/10.1007/s11469-020-00270-8.

Aliyyah, R. R., Rachmadtullah, R., Samsudin, A., Syaodih, E., Nurtanto, M., \& Tambunan, A. R. S. (2020). The perceptions of primary school teachers of online learning during the COVID-19 pandemic period: A case study in Indonesia. Journal of Ethnic Cultural Studies, 7(2), 90-109. https://doi.org/10.29333/ejecs/ 388.

Alyami, M., Henning, M., Krägeloh, C. U., \& Alyami, H. (2020). Psychometric evaluation of the Arabic version of the Fear of COVID-19 Scale. International Journal of Mental Health and Addiction, 1-14. Advance online publication. https://doi.org/10. 1007/s11469-020-00316-x.

Aperribai, L., Cortabarria, L., Aguirre, T., Verche, E., \& Borges, Á. (2020). Teacher's physical activity and mental health during lockdown due to the COVID-2019 pandemic. Frontiers in Psychology, 11, 2673. https://doi.org/10.3389/fpsyg.2020.577886

Arrindell, W. A., Urbán, R., Carrozzino, D., Bech, P., Demetrovics, Z., \& Roozen, H. G. (2017). SCL-90-R emotional distress ratings in substance use and impulse control disorders: Onefactor, oblique first-order, higher-order, and bi-factor models compared. Psychiatry Research, 255, 173-185. https://doi.org/ 10.1016/j.psychres.2017.05.019

Ashraf, B. N. (2020). Economic impact of government interventions during the COVID-19 pandemic: International evidence from financial markets. Journal of Behavioral and Experimental Finance, 27, 100371. https://doi.org/10.1016/j.jbef.2020. 100371

Asmundson, G. J. G., \& Taylor, S. (2020). Coronaphobia: Fear and the 2019-nCoV outbreak. Journal of Anxiety Disorders, 70, 102196. https://doi.org/10.1016/j.janxdis.2020.102196

Bitan, D. T., Grossman-Giron, A., Bloch, Y., Mayer, Y., Shiffman, N., \& Mendlovic, S. (2020). Fear of COVID-19 Scale: Psychometric characteristics, reliability and validity in the Israeli population. Psychiatry Research, 289, 113100. https://doi.org/ 10.1016/j.psychres.2020.113100

Bonifay, W., Lane, S. P., \& Reise, S. P. (2017). Three concerns with applying a bifactor model as a structure of psychopathology. Clinical Psychological Science, 5(1), 184-186. https://doi.org/ $10.1177 / 2167702616657069$

Bronfenbrenner, U. (1992). Ecological systems theory. Jessica Kingsley Publishers.

Cavalheiro, F. R. S., \& Sticca, M. G. (2020). Adaptation and validation of the Brazilian Version of the Fear of COVID-19 Scale. International Journal of Mental Health and Addiction. Advance online publication. doi:10.1007/s11469-020-00415-9

Caycho-Rodríguez, T., Tomás, J. M., Barboza-Palomino, M., Ventura-León, J., Gallegos, M., Reyes-Bossio, M., \& Vilca, L. W. (2021a). Assessment of fear of COVID-19 in older adults: Validation of the Fear of COVID-19 Scale. International Journal of Mental Health and Addiction, 1-15. Advance online publication. doi: 10.1007/s11469-020-00438-2 
Caycho-Rodríguez, T., Valencia, P. D., Vilca, L. W., Cervigni, M., Gallegos, M., Martino, P., Barés, I., Calandra, M., Rey Anacona, C. A., \& López-Calle, C. (2021b). Cross-cultural measurement invariance of the Fear of COVID-19 Scale in seven Latin American countries. Death Studies, 1-15. Advance online publication. doi: 10.1080/07481187.2021.1879318

Chang, K.-C., Hou, W.-L., Pakpour, A. H., Lin, C.-Y., \& Griffiths, M. D. (2020). Psychometric testing of three COVID-19-related scales among people with mental illness. International Journal of Mental Health and Addiction, 1-13. Advance online publication. doi: 10.1007/s11469-020-00361-6

Chen, F. F. (2007). Sensitivity of goodness of fit indexes to lack of measurement invariance. Structural Equation Modeling, 14(3), 464-504. https://doi.org/10.1080/10705510701301834

Chi, X., Chen, S., Chen, Y., Chen, D., Yu, Q., Guo, T., Cao, Q., Zheng, X., Huang, S., \& Hossain, M. M. (2021). Psychometric evaluation of the Fear of COVID-19 Scale among Chinese population. International Journal of Mental Health and Addiction, 1-16. Advance online publication. https://doi.org/10.1007/ s11469-020-00441-7

Dickinson, L. M., \& Basu, A. (2005). Multilevel modeling and practice-based research. Annals of Family Medicine, 3(Suppl 1), S52S60. https://doi.org/10.1370/afm.340

Dillard, J. P., Li, R., \& Yang, C. (2020). Fear of Zika: Information seeking as cause and consequence. Health Communication, 1-11. https://doi.org/10.1080/10410236.2020.1794554

Eşici, H., Ayaz, A., YetíM, D., Çağlar, S., \& Bedir, N. (2021). Teachers in COVID-19 period: Psychological effects, practices and career needs. Turkish Journal of Education, 10(2), 157-177. doi:10.19128/turje.855185

Fauzi, I., \& Khusuma, I. H. S. (2020). Teachers' elementary school in online learning of COVID-19 pandemic conditions. Jurnal Iqra': Kajian Ilmu Pendidikan, 5(1), 58-70. https://doi.org/10.25217/ ji.v5i1.914

Fisher, G. G., Matthews, R. A., \& Gibbons, A. M. (2016). Developing and investigating the use of single-item measures in organizational research. Journal of Occupational Health Psychology, 21(1), 3-23. https://doi.org/10.1037/a0039139

Fitzpatrick, K. M., Harris, C., \& Drawve, G. (2020). Fear of COVID-19 and the mental health consequences in America. Psychological Trauma: Theory, Research, Practice, and Policy, 12(S1), S17S21. https://doi.org/10.1037/tra0000924

Fornell, C., \& Larcker, D. F. (1981). Structural equation models with unobservable variables and measurement error: Algebra and statistics. Journal of Marketing Research, 18(1), 39-50. https://doi. org/10.2307/3150980

Gao, J., Zheng, P., Jia, Y., Chen, H., Mao, Y., Chen, S., . . Dai, J. (2020). Mental health problems and social media exposure during COVID-19 outbreak. PloS One, 15(4), e0231924. doi: 10.1371/ journal.pone.0231924

Gozpinar, N., Cakiroglu, S., Kalinii, E. M., Ertas, E., \& Gormez, V. (2021). Turkish version of the Fear of COVID-19 Scale: Validity and reliability study for children and adolescents. Dusunen Adam Journal of Psychiatry and Neurological Sciences, 34(1), 32-40. doi:10.14744/DAJPNS.2021.00118

Gross, J. J., \& Feldman Barrett, L. (2011). Emotion generation and emotion regulation: One or two depends on your point of view. Emotion review, 3(1), 8-16. https://doi.org/10.1177/1754073910 380974

Hair, J. F., Black, W. C., Babin, B. J., \& Anderson, R. E. (2019). Multivariate data analysis (Ed. 8th). Hampshire: Cengage Learning EMEA.

Harper, C. A., Satchell, L. P., Fido, D., \& Latzman, R. D. (2020). Functional fear predicts public health compliance in the COVID-19 pandemic. Advance online publication. International Journal of Mental Health and Addiction. doi:10.1007/s11469-020-00281-5.
Han, J.-W., Park, J., \& Lee, H. (2021). Validity and reliability of the Korean version of the Fear of COVID-19 Scale. International Journal of Environmental Research and Public Health, 18(14), 7402. https://doi.org/10.3390/ijerph18147402

He, Y. P., \& Li, D. B. (2020). School mental health education in the social psychological service system. Zhōng Xiǎo Xué Xīn Lì Jiàn Kāng Jiāo Yù, 27, 28-31 (in Chinese).

Ho, S. M., Kwong-Lo, R. S., Mak, C. W., \& Wong, J. S. (2005). Fear of severe acute respiratory syndrome (SARS) among health care workers. Journal of Consulting and Clinical Psychology, 73(2), 344-349. https://doi.org/10.1037/0022-006X.73.2.344

Huarcaya-Victoria, J., Villarreal-Zegarra, D., Podestà, A., \& LunaCuadros, M. A. (2020). Psychometric properties of a Spanish version of the Fear of COVID-19 Scale in general population of Lima, Peru. International Journal of Mental Health and Addiction, 1-14. Advance online publication. https://doi.org/10.1007/ s11469-020-00354-5.

Iversen, M. M., Norekvål, T. M., Oterhals, K., Fadnes, L. T., Mæland, S., Pakpour, A. H., \& Breivik, K. (2021). Psychometric properties of the Norwegian version of the Fear of COVID-19 Scale. International Journal of Mental Health and Addiction, 1-19. Advance online publication. https://doi.org/10.1007/s11469-020-00454-2.

Kaartina, S., Chin, Y. S., Wahida, R. F., Woon, F. C., Hiew, C. C., Zalilah, M. S., \& Nasir, M. T. M. (2015). Adolescent selfreport and parent proxy-report of health-related quality of life: an analysis of validity and reliability of PedsQL ${ }^{\mathrm{TM}} 4.0$ among a sample of Malaysian adolescents and their parents. Health and Quality of Life Outcomes, 13(1), 1-9. https://doi.org/10.1186/ s12955-015-0234-4

Kaden, U. (2020). COVID-19 school closure-related changes to the professional life of a K-12 Teacher. Education Sciences, 10(6), 165. doi: 10.3390/educsci10060165

Khanal, P., Bento, F., \& Tagliabue, M. (2021). A scoping review of organizational responses to the COVID-19 pandemic in schools: A complex systems perspective. Education Sciences, 11(3), 115. doi: 10.3390/educsci11030115

Lazarus, R. S. (1991). Cognition and motivation in emotion. American Psychologist, 46(4), 352-367. doi: 10.1037/0003-066X.46.4. 352

Lepp, L., Aaviku, T., Leijen, Ä., Pedaste, M., \& Saks, K. (2021). Teaching during COVID-19: The decisions made in teaching. Education Sciences, 11(2), 47. doi:10.3390/educsci11020047

Li, C.-H. (2016). Confirmatory factor analysis with ordinal data: Comparing robust maximum likelihood and diagonally weighted least squares. Behavior Research Methods, 48(3), 936-949. https://doi. org/10.3758/s13428-015-0619-7

Li, Q., Miao, Y., Zeng, X., Tarimo, C. S., Wu, C., \& Wu, J. (2020). Prevalence and factors for anxiety during the coronavirus disease 2019 (COVID-19) epidemic among the teachers in China. Journal of Affective Disorders, 277, 153-158. https://doi.org/10.1016/j. jad.2020.08.017

Li, R. (2021). Fear of COVID-19: What causes fear and how individuals cope with it. Health Communication. Advance online publication. doi:10.1080/10410236.2021.1901423

Lin, C.-Y. (2020). Social reaction toward the 2019 novel coronavirus (COVID-19). Asian Journal of Social Health and Behavior, 3(1), 1. https://doi.org/10.4103/SHB.SHB_11_20

Lin, C.-Y., Broström, A., Griffiths, M. D., \& Pakpour, A. H. (2020). Investigating mediated effects of fear of COVID-19 and COVID19 misunderstanding in the association between problematic social media use, psychological distress, and insomnia. Internet Interventions, 21, 100345. https://doi.org/10.1016/j.invent.2020. 100345

Lin, C. Y., Hou, W. L., Mamun, M. A., Aparecido da Silva, J., BrochePérez, Y., Ullah, I., ... \& Pakpour, A. H. (2021). Fear of COVID19 Scale (FCV-19S) across countries: Measurement invariance 
issues. Nursing Open, 1-17. Advance online publication. https:// doi.org/10.1002/nop2.855

Loong, M. L. H. (2021). The COVID-19 situation in Singapore. April 3. https://www.gov.sg/article/pm-lee-hsien-loong-on-the-covid19-situation-in-singapore-3-apr

Lovibond, S. H., \& Lovibond, P. F. (1996). Manual for the depression anxiety stress scales. Psychology Foundation of Australia.

MacIntyre, P. D., Gregersen, T., \& Mercer, S. (2020). Language teachers' coping strategies during the Covid-19 conversion to online teaching: Correlations with stress, wellbeing and negative emotions. System, 94, 102352. https://doi.org/10.1016/j.system.2020. 102352

Mahmood, Q. K., Jafree, S. R., \& Qureshi, W. A. (2020). The psychometric validation of FCV-19S in Urdu and socio-demographic association with fear in the people of the Khyber Pakhtunkhwa (KPK) Province in Pakistan. International Journal of Mental Health and Addiction. https://doi.org/10.1007/ s11469-020-00371-4

Magano, J., Vidal, D. G., Sousa, H. F., Dinis, M. A., \& Leite, Â. (2021). Validation and psychometric properties of the Portuguese version of the Coronavirus Anxiety Scale (CAS) and Fear of COVID19 Scale (FCV-19S) and associations with travel, tourism and hospitality. International Journal of Environmental Research and Public Health, 18(2), 427. https://doi.org/10.3390/ijerph18020427

Masuyama, A., Shinkawa, H., \& Kubo, T. (2020). Validation and psychometric properties of the Japanese version of the Fear of COVID-19 Scale among adolescents. International Journal of Mental Health and Addiction, 1-11. Advance online publication https://doi.org/10.1007/s11469-020-00368-z.

Mari, E., Lausi, G., Fraschetti, A., Pizzo, A., Baldi, M., Quaglieri, A., . . G Giannini, A. M. (2021). Teaching during the pandemic: A comparison in psychological wellbeing among smart working professions. Sustainability, 13(9), 4850. https://doi.org/10.3390/ su13094850.

Mertens, G., Gerritsen, L., Duijndam, S., Salemink, E., \& Engelhard, I. M. (2020). Fear of the coronavirus (COVID-19): Predictors in an online study conducted in March 2020. Journal of Anxiety Disorders, 74, 102258. https://doi.org/10.1016/j.janxdis.2020.102258

Michalova, N., Yusfin, S., \& Polyakov, S. (2002). Using action research in current conditions of russian teacher education. Educational Action Research, 10(3), 423-448. https://doi.org/10.1080/09650 790200200194

Midorikawa, H., Aiba, M., Lebowitz, A., Taguchi, T., Shiratori, Y., Ogawa, T., Takahashi, A., Takahashi, S., Nemoto, K., \& Arai, T. (2021). Confirming validity of The Fear of COVID-19 Scale in Japanese with a nationwide large-scale sample. PloS One, 16(2), e0246840. https://doi.org/10.1371/journal.pone.0246840

Netemeyer, R. G., Bearden, W. O., \& Sharma, S. (2003). Scaling procedures: Issues and applications. Sage Publications.

Neal, J. W., \& Neal, Z. P. (2013). Nested or networked? Future directions for ecological systems theory. Social Development, 22(4), 722-737. https://doi.org/10.1111/sode. 12018

Nilson, L. B., \& Goodson, L. A. (2021). Online teaching at its best: Merging instructional design with teaching and learning research: John Wiley \& Sons.

Renn, O., Burns, W. J., Kasperson, J. X., Kasperson, R. E., \& Slovic, P. (1992). The social amplification of risk: Theoretical foundations and empirical applications. Journal of Social Issues, 48(4), 137-160. https://doi.org/10.1111/j.1540-4560.1992.tb01949.x.

Nkwayep, C. H., Bowong, S., Tewa, J., \& Kurths, J. (2020). Shortterm forecasts of the COVID-19 pandemic: A study case of Cameroon. Chaos, Solitons \& Fractals, 140, 110106. https://doi.org/ 10.1016/j.chaos.2020.110106

Pak, A., Adegboye, O. A., Adekunle, A. I., Rahman, K. M., McBryde, E. S., \& Eisen, D. P. (2020). Economic consequences of the COVID-19 outbreak: The need for epidemic preparedness.
Frontiers in Public Health, 8, 241. https://doi.org/10.3389/fpubh. 2020.00241

Pakpour, A. H., Griffiths, M. D., Chang, K.-C., Chen, Y.-P., Kuo, Y.-J., \& Lin, C.-Y. (2020). Assessing the fear of COVID-19 among different populations: A response to Ransing et al.(2020). Brain, Behavior, and Immunity, 89, 524-525. https://doi.org/10.1016/j. bbi.2020.06.006

Piroth, L., Cottenet, J., Mariet, A.-S., Bonniaud, P., Blot, M., Tubert-Bitter, P., \& Quantin, C. (2021). Comparison of the characteristics, morbidity, and mortality of COVID-19 and seasonal influenza: a nationwide, population-based retrospective cohort study. The Lancet Respiratory Medicine, 9(3), 251-259. https://doi.org/10.1016/S2213-2600(20)30527-0

Ransing, R., Ramalho, R., Orsolini, L., Adiukwu, F., Gonzalez-Diaz, J. M., Larnaout, A., . . . Kilic, O. (2020). Can COVID-19 related mental health issues be measured? Brain, Behavior, and Immunity, 88, 32-34. https://doi.org/10.1016/j.bbi.2020.05.049.

Rodriguez, A., Reise, S. P., \& Haviland, M. G. (2016). Applying bifactor statistical indices in the evaluation of psychological measures. Journal of Personality Assessment, 98(3), 223-237. https://doi.org/10.1080/00223891.2015.1089249

Rodríguez-Hidalgo, A. J., Pantaleón, Y., Dios, I., \& Falla, D. (2020). Fear of COVID-19, stress, and anxiety in university undergraduate students: A predictive model for depression. Frontiers in Psychology, 11, 591797. https://doi.org/10.3389/fpsyg.2020. 591797

Sakib, N., Bhuiyan, A. I., Hossain, S., Al Mamun, F., Hosen, I., Abdullah, A. H., Sarker, M. A., Mohiuddin, M. S., Rayhan, I., \& Hossain, M. (2020). Psychometric validation of the Bangla Fear of COVID-19 Scale: Confirmatory factor analysis and Rasch analysis. International Journal of Mental Health and Addiction, 1-12. Advance online publication.doi: 10.1007/s11469-020-00289-x

Satici, B., Gocet-Tekin, E., Deniz, M. E., \& Satici, S. A. (2020). Adaptation of the Fear of COVID-19 Scale: Its association with psychological distress and life satisfaction in Turkey. International Journal of Mental Health and Addiction. Advance online publication. doi:10.1007/s11469-020-00294-0

Schimmenti, A., Billieux, J., \& Starcevic, V. (2020). The four horsemen of fear: An integrated model of understanding fear experiences during the COVID-19 pandemic. Clinical Neuropsychiatry, 17(2), 41-45. doi: $10.36131 / \mathrm{CN} 20200202$

Shen, Q., Gui, Y., \& Zhou, X. H. (2020). Investigation and research on the effectiveness of online "teaching" and "learning" in primary and secondary schools during the epidemic period. Zhōng Guó Diàn Huà Jiāo Yù, 5, 34-43 (in Chinese).

Shin, L., \& Liberzon, I. (2010). The neurocircuitry of fear, stress, and anxiety disorders. Neuropsychopharmacology, 35(1), 169-191. https://doi.org/10.1038/npp.2009.83

Soares, F. R., Afonso, R. M., Martins, A. P., Pakpour, A. H., \& Rosa, C. P. (2021). The Fear of COVID-19 Scale: Validation in the Portuguese general population. Death Studies, 1-7. Advance online publication. https://doi.org/10.1080/07481187.2021.1889722.

Soraci, P., Ferrari, A., Abbiati, F. A., Del Fante, E., De Pace, R., Urso, A., \& Griffiths, M. D. (2020). Validation and psychometric evaluation of the Italian version of the Fear of COVID-19 Scale. International Journal of Mental Health and Addiction, 1-10. Advance online publication. https://doi.org/10.1007/s11469-020-00277-1.

Superio, D. L., Anderson, K. L., Oducado, R. M. F., Luceño, M. T., Palcullo, V. E. V., \& Bendalian, M. V. T. (2021). The informationseeking behavior and levels of knowledge, precaution, and fear of college students in Iloilo, Philippines amidst the COVID-19 pandemic. International Journal of Disaster Risk Reduction, 62, 102414. https://doi.org/10.1016/j.ijdrr.2021.102414.

Taylor, S., Landry, C. A., Paluszek, M. M., Fergus, T. A., McKay, D., \& Asmundson, G. J. G. (2020). Development and initial validation 
of the COVID Stress Scales. Journal of Anxiety Disorders, 72, 102232. https://doi.org/10.1016/j.janxdis.2020.102232

Trizano-Hermosilla, I., \& Alvarado, J. M. (2016). Best alternatives to Cronbach's alpha reliability in realistic conditions: congeneric and asymmetrical measurements. Frontiers in Psychology, 7, 769. https://doi.org/10.3389/fpsyg.2016.00769

Tull, M. T., Edmonds, K. A., Scamaldo, K. M., Richmond, J. R., Rose, J. P., \& Gratz, K. L. (2020). Psychological outcomes associated with stay-at-home orders and the perceived impact of COVID-19 on daily life. Psychiatry Research, 289, 113098. https://doi.org/ 10.1016/j.psychres.2020.113098

Voice of America News (2021). Japan extends COVID-19 state of emergency to May 31. https://www.voanews.com/covid-19-pande mic/japan-extends-covid-19-state-emergency-may-31

Wakashima, K., Asai, K., Kobayashi, D., Koiwa, K., Kamoshida, S., \& Sakuraba, M. (2020). The Japanese version of the Fear of COVID19 Scale: Reliability, validity, and relation to coping behavior. PloS One, 15(11), e0241958. https://doi.org/10.1371/journal. pone. 0241958

Wheaton, M. G., Abramowitz, J. S., Berman, N. C., Fabricant, L. E., \& Olatunji, B. O. (2012). Psychological predictors of anxiety in response to the H1N1 (swine flu) pandemic. Cognitive Therapy and Research, 36(3), 210-218. https://doi.org/10.1007/ s10608-011-9353-3

Wild, B., Erb, M., \& Bartels, M. (2001). Are emotions contagious? Evoked emotions while viewing emotionally expressive faces: quality, quantity, time course and gender differences. Psychiatry Research, 102(2), 109-124. https://doi.org/10.1016/S01651781(01)00225-6

Wilson, T. D., Ford, N. J., Ellis, D., Foster, A. E., \& Spink, A. (2002). Information seeking and mediated searching: Part 2. Uncertainty and its correlates. Journal of the American Society for Information Science and Technology, 53(9), 704-715. https://doi.org/10. 1002/asi.10082.
Winter, T., Riordan, B. C., Pakpour, A. H., Griffiths, M. D., Mason, A., Poulgrain, J. W., \& Scarf, D. (2020). Evaluation of the English version of the Fear of COVID-19 Scale and its relationship with behavior change and political beliefs. International Journal of Mental Health and Addiction, 1-11. Advance online publication. https://doi.org/10.1007/s11469-020-00342-9.

World Health Organization (2021a). Coronavirus disease (COVID-19) pandemic. https://www.euro.who.int/en/health-topics/healthemergencies/coronavirus-covid-19/novel-coronavirus-2019-ncov

World Health Organization (2021b). Weekly epidemiological update - 16 February 2021. https://www.who.int/publications/m/item/ weekly-epidemiological-update\%2D\%2D-16-february-2021

World Health Organization (2021c). Viet Nam COVID-19 Situation Report \#41. https://www.who.int/docs/default-source/wpro\%2D\% 2D-documents/countries/viet-nam/covid-19/viet-nam-moh-whocovid-19-sitrep_9may2021.pdf?sfvrsn=8bfdf5d0_5\&download= true

Yao, Y. (2021). Epidemic issues are often resolved, and mental health is guaranteed. Zhōng Xiăo Xué Xīn Lǐ Jiàn Kāng Jiāo Yù, 7, 64-65 (in Chinese).

Yoon, M., \& Lai, M. H. C. (2018). Testing factorial invariance with unbalanced samples. Structural Equation Modeling, 25(2), 201213. https://doi.org/10.1080/10705511.2017.1387859

Zheng, Z., \& Song, N. (2020). The real dilemma of online teaching in primary and secondary schools in Western China and its beyond path. Xiăo Xué Xīn Lì Jiàn Kāng Jiāo Yù, 12, 22-28 (in Chinese).

Zhou, L., \& Li, F. (2020). A review of the largest online teaching in China for elementary and middle school students during the COVID-19 pandemic. Best Evidence in Chinese Education, 5(1), 549-567. https://doi.org/10.15354/bece.20.re040.

Publisher's Note Springer Nature remains neutral with regard to jurisdictional claims in published maps and institutional affiliations. 